\title{
CDK5 inhibition in vitro and in vivo induces cell death in myeloma and overcomes the obstacle of bortezomib resistance
}

\author{
HAILONG TANG $^{1 *}$, LI XU $^{1 *}$, XI CEN $^{2 *}$, LI YANG $^{3}$, JUAN FENG $^{1}$, GUANG LI $^{1}$, HUAFENG ZHU $^{1}$, SHAN GAO $^{1}$, \\ YAN YU $^{1}$, YAPING ZHAO ${ }^{1}$, ZHIQIANG TIAN ${ }^{1}$, LIPING HOU ${ }^{1}$, SHUCHUN YU ${ }^{1}$ and GUANGXUN GAO ${ }^{1}$ \\ ${ }^{1}$ Department of Hematology, Xijing Hospital, Fourth Military Medical University, Xi'an, Shaanxi 710032, P.R. China; \\ ${ }^{2}$ Department of Public Health Sciences, University of Rochester, Rochester, NY 14642, USA; ${ }^{3}$ Department of Pathology, \\ Xijing Hospital, Fourth Military Medical University, Xi'an, Shaanxi 710032, P.R. China
}

Received October 6, 2019; Accepted January 15, 2020

DOI: $10.3892 /$ ijmm.2020.4553

\begin{abstract}
The emergence of new drugs is a major feature of the treatment history of multiple myeloma (MM), which also reflects the current incurability of MM. As a unique member of cyclin dependent kinase (CDK) family, CDK5 participates in numerous tumorigenic or non-tumorigenic processes. The aim of this study is to investigate the effects of CDK5 on the viability of MM cells and bortezomib resistance using western blotting, immunohistochemistry, transient transfection, MTT assays, cell cycle analysis, apoptosis assays and a myeloma xenograft mouse model. The present study found that MM patients with high CDK5 expression in the bone marrow do not respond well to bortezomib, have higher DS stage and worse prognosis. Genetic and pharmacological (dinaciclib) inhibition of CDK5 triggers MM cell viability inhibition. Dinaciclib induces G2/M arrest and apoptosis of MM cells. In vivo experiments with myeloma xenograft mice indicate that dinaciclib significantly reduces the volume of tumors with good tolerance. Dinaciclib combined with bortezomib exerts a synergistic anti-myeloma activity accompanied by inhibiting the activation of the nuclear factor- $\kappa \mathrm{B}$ pathway. This study demonstrates the important role of CDK5 in the pathogenesis, viability, prognosis and resistance to bortezomib of MM, laying a solid theoretical foundation for further clinical use of CDK5 inhibitors.
\end{abstract}

Correspondence to: Professor Guangxun Gao, Department of Hematology, Xijing Hospital, Fourth Military Medical University, 127 Changle Road, Xincheng, Xi'an, Shaanxi 710032, P.R. China

E-mail: gaoguangxun@fmmu.edu.cn

*Contributed equally

Key words: multiple myeloma, cyclin dependent kinase 5, prognosis, bortezomib, NF-кB pathway, synergistic effect

\section{Introduction}

Cyclin-dependent kinases (CDKs) are a group of serine/threonine protein kinases family members whose main biological functions are to regulate the cell cycle and transcription $(1,2)$. CDK5, as an atypical member of the CDKs family, is orchestrated by p35/p39 (3) and hence does not directly regulate the cell cycle, but plays an essential role in neurodevelopment and neurotransmission. In addition to its role in the nervous system, CDK 5 also participates in numerous tumorigenic or non-tumorigenic pathophysiological processes, including mediating cell migration, apoptosis, cell cycle processes, as well as regulating the immune system, angiogenesis, insulin secretion and tumorigenesis (4).

Previous studies showed that aberrant expression of CDK5 had been observed in multiple human cancers, but not in normal tissues. CDK5 were positively correlated with lymph node metastasis and the stage of disease in head and neck squamous cell carcinoma, cervical lesions, lung cancer, hepatocellular carcinoma and nasopharyngeal carcinoma (5-10), and its overexpression was also associated with the poor prognosis in colorectal cancer and breast cancer $(7,8)$. Tumor tissues with high expression of CDK5 are usually insensitive to chemoradiotherapy and targeted therapy $(11,12)$. Therefore, targeting CDK5 may circumvent the drawbacks of the current therapies $(13,14)$.

Multiple myeloma (MM) is an incurable plasma cell malignancy in bone marrow. The emergence of proteasome inhibitor bortezomib is a milestone in the history of MM therapy. However, most patients will eventually relapse, which can be partly put down to resistance to bortezomib. Therefore, the exploration of new drugs which can overcome the barrier of bortezomib resistance is one of the main focuses of MM treatment. At present, the studies on the relationship between CDK5 and cancer are mostly limited to solid tumors. A small quantity of studies have shown that high expression of CDK5 is associated with poor prognosis and bortezomib resistance in MM patients, so further exploration of the specific mechanism is still needed (15-17).

Dinaciclib is a specific inhibitor of CDK1/2/5/9.Pre-clinical and early clinical studies have confirmed that dinaciclib is a promising anti-myeloma drug (18-20). The purpose of this 
study is to further explore the influence of CDK5 expression on prognosis, bortezomib response in MM patients and to uncover the deep synergistic anti-myeloma mechanism of dinaciclib and bortezomib. These studies will lay a solid theoretical foundation for dinaciclib in clinical treatment of MM.

\section{Materials and methods}

Cell culture and reagents. The isolation of primary MM cells from patients and bone marrow mononuclear cells (BMMCs) from healthy donors was carried out according to the authors' previous study (21). Human MM cell lines (RPMI8226, H929, MM.1S and U226), primary MM cells from patients and BMMCs from healthy donors were cultured in RPMI-1640 medium (Hyclone; GE Healthcare) containing 10\% fetal bovine serum (Gibco; Thermo Fisher Scientific, Inc.), 100 units/ml penicillin, $100 \mathrm{mg} / \mathrm{ml}$ streptomycin, $2 \mathrm{mM} \mathrm{L}$-glutamine and $5 \% \mathrm{CO}_{2}$ at $37^{\circ} \mathrm{C}$. Informed consent was obtained from all patients, in accordance with the Helsinki Protocol. These studies have been approved by the Ethics Committee of Xijing Hospital. Dinaciclib was provided by Selleck Chemicals. Bortezomib was obtained from Selleck Chemicals.

Western blotting. Cells were lysed with RIPA buffer (Beyotime Institute of Biotechnology) and the concentration of protein was assessed using a bicinchoninic acid assay (Beyotime Institute of Biotechnology). A total of $20 \mu \mathrm{g}$ supernatants were subjected to 10 or $12 \%$ sodium dodecyl sulfate polyacrylamide gel electrophoresis and transferred to PVDF followed by blocking in TBS containing 5\% non-fat milk for $1 \mathrm{~h}$ at room temperature. Immunoblotting was performed overnight at $4^{\circ} \mathrm{C}$ using antibodies against CDK5 (1:10,000; cat. no. ab40773; Abcam), CDK1 (1:10,000; cat. no. ab133327; Abcam), CDK2 (1:5,000; cat. no. ab32147: Abcam), CDK9 (1:5,000; ab76320, Abcam), CDC25c (1:2,000; cat. no. ab32444; Abcam), cyclin B1 (1:50,000; cat. no. ab32053; Abcam), cyclin D1 (1:50,000; cat. no. ab134175; Abcam), cyclin E1 (1:2,000; cat. no. ab133266; Abcam), p21 (1:5,000; cat. no. ab109520; Abcam), p16 (1:2,000; cat. no. ab108349; Abcam), p65 (1:5,000; cat. no. ab32536; Abcam), phosphorylated- IкB kinase (p-) IKK $\alpha$ (1:500; cat. no. ab38515; Abcam), IKK $\alpha(1: 10,000$; cat. no. ab32041; Abcam), p-IкB $\alpha$ (1:5,000; cat. no. ab133462; Abcam), IкB $\alpha$ (1:5,000; cat. no. ab32518; Abcam), Bcl-2 (1:500; cat. no. ab32124; Abcam), Bcl-xL (1:500; cat. no. ab32370: Abcam), Lamin B (1:5,000; cat. no. ab133741; Abcam), $\beta$-actin (1:2,000; cat. no. ab8226; Abcam), GAPDH (1:5,000; cat. no. ab9484; Abcam) and cleaved poly (ADP-ribose) polymerase (PARP; 1:2,000; cat. no. 5625; Cell Signaling Technology, Inc.), cleaved caspase 8 (1:1,000; cat. no. 8592; Cell Signaling Technology, Inc.), cleaved caspase 9 (1:500; cat. no. 20750; Cell Signaling Technology, Inc.), cleaved caspase 3 (1:500; cat. no. 9661; Cell Signaling Technology, Inc.) and CDC2 (1:1,000; cat. no. 9116; Cell Signaling Technology, Inc.). Then blots were incubated with goat anti-rabbit horseradish peroxidase-conjugated secondary antibodies (1:4,000; cat. no. ab7090; Abcam) at room temperature for $1 \mathrm{~h}$. were developed by chemiluminescence using SuperSignal reagent (EMD Millipore). To prepare nuclear and cytosolic protein extracts, the harvested cells were resuspended in cytosolic protein lysis buffer (Beyotime Institute of Biotechnology) on ice for $15 \mathrm{~min}$. After being centrifuged for $5 \mathrm{~min}$ at $16,000 \mathrm{xg}$ at $4^{\circ} \mathrm{C}$, the supernatant was collected as cytosolic protein extracts. Then the cell nuclear pellets were resuspended in nuclear protein extraction buffer on ice for $40 \mathrm{~min}$ and centrifuged for $5 \mathrm{~min}$ at $16,000 \mathrm{x}$ g at $4^{\circ} \mathrm{C}$. The supernatant was collected as nuclear protein extracts.

Immunohistochemistry (IHC). Bone marrow biopsies of $65 \mathrm{MM}$ patients treated with bortezomib and 10 healthy donors were obtained in Xijing Hospital (Fourth Military Medical University) from January 2012 to January 2019 All patients and donors signed informed consent. The clinical data, cytogenetic abnormalities and immunophenotypes of all patients were collected from the medical records system in our hospital. Patient characteristics are shown in Table I. The IHC staining of CDK5 and scoring were carried out as previously described (6). The cutoff value of CDK5 was selected according to the analysis of overall survival (OS). The score of $>4$ was defined as high expression of CDK5 and $<4$ as low expression of CDK5.

Transient transfection. RPMI 8226 cells were transiently transfected with genome scramble-siRNA or siRNA against CDK5 (Smart pool siRNA; GE Healthcare Dharmacon, Inc.) using Nucleofector kit $\mathrm{V}$ in accordance with the manufacturer's protocol (Amaxa Biosystems). CDK5-siRNA was designed with Block-iT RNAi Designer (Invitrogen; Thermo Fisher Scientific, Inc,) and synthesized (Wuhan GeneCreate Biological Engineering Co., Ltd.). The sequences of CDK5-siRNA were 5'-CCTTATAGTCTGGCAGCTT-3' and the scramble shRNA sequences were 5'-CCTATTGTCGGA CGTACTT-3'. After $48 \mathrm{~h}$ of transfection with $100 \mathrm{nM}$ siRNA (shRNA $10 \mathrm{pmol} / \mathrm{sample}$ ), the cells were collected for CDK5 expression and cell viability detection.

Cell viability assay. MM cell lines, primary MM cells and normal BMMCs were inoculated into 96-well plates $\left(1 \times 10^{4}\right.$ cells/well) and treated with different concentrations of dinaciclib according to indicated experimental design. After incubation with $10 \mu 15 \mathrm{mg} / \mathrm{ml}$ MTT for $4 \mathrm{~h}, 100 \mu 1$ DMSO was added after the supernatant was removed by centrifugation at a speed of $114 \mathrm{x} \mathrm{g}$ for $15 \mathrm{~min}$ at room temperature and the absorbance value was measured at $570 \mathrm{nM}$ using a spectrophotometer.

Cell cycle analysis. MM cells were seeded in a 6-well plate $\left(10 \times 10^{4}\right.$ cells/well) and incubated with various doses of dinaciclib for $24 \mathrm{~h}$, washed twice with PBS and fixed with $70 \%$ ice ethanol at $-20^{\circ} \mathrm{C}$ for $24 \mathrm{~h}$. Cells were washed twice with PBS and incubated with $1 \mathrm{mg} / \mathrm{ml} \mathrm{RNase} A$ at $37^{\circ} \mathrm{C}$ for $20 \mathrm{~min}$. Finally, PI ( $50 \mu \mathrm{g} / \mathrm{ml}$; Sigma-Aldrich; Merck KGaA) was added to incubate at room temperature for $20 \mathrm{~min}$ and then Epics XL flow cytometry (Beckman Coulter, Inc.) was used to detect the cell cycle distribution. At least 10,000 events per group were measured within an acquisition rate of 100-300 events/sec. Data were analyzed by FlowJo. 7.6.1 software (Flowjo, LLC).

Apoptosis assay. MM cells were seeded in a 6-well plate $\left(10 \times 10^{4}\right.$ cells/well) and incubated with various doses of dinaciclib for $24 \mathrm{~h}$. Cell apoptosis was detected with Annexin V-PI 
Staining kit (BD Biosciences; Becton, Dickinson and Company) in accordance with the manufacturer's protocol.

Myeloma xenograft mouse model. A total of 20 male Balb/C athymic nude (weight, $15 \mathrm{~g}$; age, 4-6 weeks) were obtained from the Core Animal Facility of Fourth Military Medical University and were maintained under pathogen-free conditions $\left(25^{\circ} \mathrm{C} ; 50 \%\right.$ humidity; $12 \mathrm{~h}$ light/dark cycle $)$ and access to food and water. RPMI8226 cells $\left(1 \times 10^{7}\right)$ were suspended in $80 \mu \mathrm{l}$ serum-free RPMI1640 medium and mixed with $70 \mu \mathrm{l}$ matrix glue (BD Biosciences; Becton, Dickinson and Company). A total of $150 \mu \mathrm{l}$ suspension was subcutaneously injected into the right lower limb of mice and the tumor formation rate was $30 \%(6 / 20)$. When the tumors were measurable (100-150 $\left.\mathrm{mm}^{3}\right)$ after $\sim$ two weeks, mice were randomly divided into two groups ( 3 for each group): Control group (equal volume of vehicle) and dinaciclib group (intraperitoneal injection, $45 \mathrm{mg} / \mathrm{kg}$, 4 days a week) (19). The size of the tumors and the weight of mice were measured every three days with vernier calipers. All the six mice were euthanized by cervical dislocation $\sim 6$ weeks after the cell injection and tumor xenografts were carefully excised for further use after the heartbeat and respiratory arrest of the mice. The volume was calculated by the following formula: $\mathrm{V}=0.5 \mathrm{xaxb}^{2}$, $\mathrm{a}$ and $\mathrm{b}$ were the length and width of the tumors respectively. Apoptosis of tumors excised from mice was detected by TUNEL staining and hematoxylin and eosin staining ( $3 \mathrm{~min}$ in the two dyes respectively at room temperature). The expression of CDK5 was detected by immunohistochemistry. All the animal studies performed were approved by the Animal Ethics Committee of Fourth Military Medical University (Xi'an, China).

TUNEL staining. The in situ cell death detection kit, POD (cat. no. 11684817910; Roche Diagnostics GmbH), was used for TUNEL staining in accordance with the manufacturer's protocol. paraffin-embedded specimens were de-paraffinized using dimethylbenzene twice, rehydrated with a gradient elution of alcohol (100, 95, 90, 80 and 70\%) and permeabilized using proteinase $\mathrm{K}$ at $37^{\circ} \mathrm{C}$ for $10 \mathrm{~min}$. Sections were subsequently treated with $50 \mu \mathrm{l}$ TUNEL reaction mixture for $60 \mathrm{~min}$ in a humidified container at $37^{\circ} \mathrm{C}$ in the dark. Sections were then incubated with $50 \mu \mathrm{l}$ converter-POD at $37^{\circ} \mathrm{C}$ in the dark for $30 \mathrm{~min}$. A total of $50 \mu \mathrm{l} \mathrm{DAB}$ was added to the sections for $10 \mathrm{~min}$ at room temperature followed by hematoxylin staining for $3 \mathrm{sec}$ at room temperature. Apoptotic cells were viewed using a light microscope (Olympus Corporation) at x400 magnification. Five random fields of view were captured for each section and the total nuclei and TUNEL-positive nuclei were counted.

Synergetic effect analysis. Three concentrations <IC50 (50\% of inhibiting concentration) of dinaciclib (MM cell lines: 0, 1, 2.5 and $5 \mathrm{nM}$ and primary MM cells: $0,10,25,50 \mathrm{nM})$ and bortezomib (MM cell lines: 0, 0.5, 1 and $2 \mathrm{nM}$ and primary MM cells: 0, 5, 10 and $20 \mathrm{nM}$ ) were chosen. The inhibition rates of MM cell lines and primary MM cells treated with individual drugs or the drug combination were calculated by MTT method. Calcusyn software 2.0 (Premier Biosoft International) was used to analyze the reduction indices and isobologram plots. $\mathrm{CI}<1$ represents synergism, $\mathrm{CI}>1$ represents antagonism.
Statistical analysis. All data was determined by GraphPad Prism5 software (GraphPad Software, Inc.). Survival curves were plotted by the Kaplan-Meier method and compared using log-rank test. A two-tailed independent Student's t-test was used for analyzing two groups. A Chi square test was used to analyze the relationship between CDK5 expression and the clinicopathological features, cytogenetic abnormalities or immunophenotypes of MM. All data were presented as the mean \pm standard deviation from at least three independent experiments. $\mathrm{P}<0.05$ was considered to indicate a statistically significant difference.

\section{Results}

CDK5 expression and prognostic relevance in MM. Western blot results showed that the expression of CDK5 in MM cells from patients (patient 1-4) and multiple MM cell lines was significantly increased compared with normal BMMCs (Figs. 1A and S1A). Similar results were observed using immunohistochemical staining of bone marrow biopsies from 65 newly diagnosed MM patients treated with bortezomib induction therapy and healthy donors (Fig. 1B). To understand the potential roles of CDK5 in the development of MM, the correlation of CDK5 expression with the clinical indicators, cytogenetic abnormalities and immunophenotype was analyzed and the results showed that high expression of CDK5 was correlated with the high DS stage $(\mathrm{P}=0.026)$, but not with other indicators (including gender, age, clinicopathological characteristics, cytogenetic abnormalities and immunophenotype; Tables I and II). Kaplan-Meier survival analysis showed a significant correlation between high CDK5 expression and poor overall survival statistically in $\mathrm{MM}$ patients $(\mathrm{P}=0.003$; Fig. 1C). Next, an siRNA strategy was used to evaluate the importance of CDK5 for MM cell viability. A marked down expression of CDK5 was observed by CDK5 smart pool siRNAs compared with scrambled siRNA in RPMI8226 cells (Figs. 1D and S1B). MTT results showed that the viability of MM cells transfected with CDK5 siRNA was inhibited compared with scramble siRNA (Fig. 1E). These results revealed that CDK5 might be involved in the pathogenesis of $\mathrm{MM}$ and had a prognostic relevance in $\mathrm{MM}$, providing a rationale for targeting CDK5 in MM.

Effect of dinaciclib on the viability of MM cells in vitro. Dinaciclib is a small molecule CDK1/2/5/9 inhibitor, but the IC50 is different for distinct target molecules. The present study evaluated the expression of CDK1/2/5/9 in RPMI8226 and $\mathrm{H} 929$ cell lines treated with different concentrations $(0,1,2$ and $5 \mathrm{nM})$ of dinaciclib. A total of $5 \mathrm{nM}$ dinaciclib significantly downregulated the expression of CDK 5 without affecting that of other target molecules (Fig. S2). Therefore, dinaciclib could be used as a selective inhibitor of CDK5 to explore its effect on the biological function in MM cells.

Firstly, various MM cell lines (RPMI 8226, H929, MM. 1S and U226), primary MM cells and BMMCs from healthy people were treated with different concentrations of dinaciclib for $24 \mathrm{~h}$, followed by cell viability assessment. A concentration-dependent decrease of cell viability was observed in all MM cell lines in response to dinaciclib (Fig. 2A). Dinaciclib also significantly inhibited the viability 

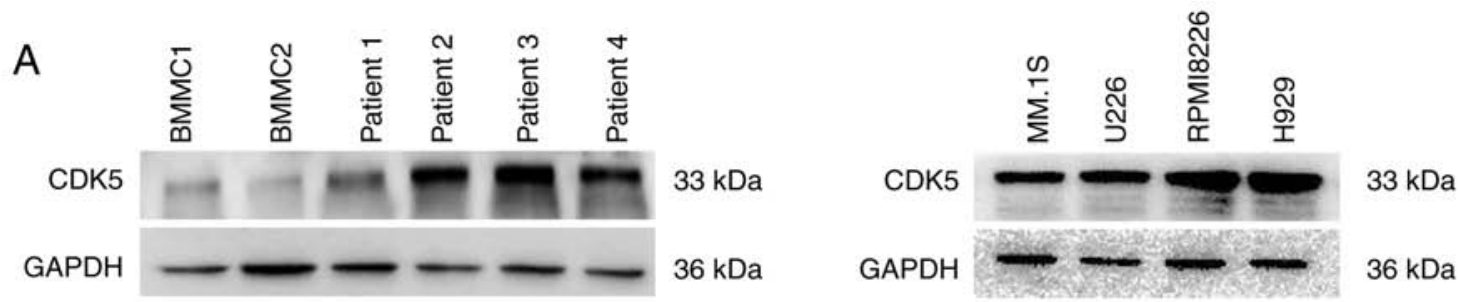

B

Normal donor

MM patients
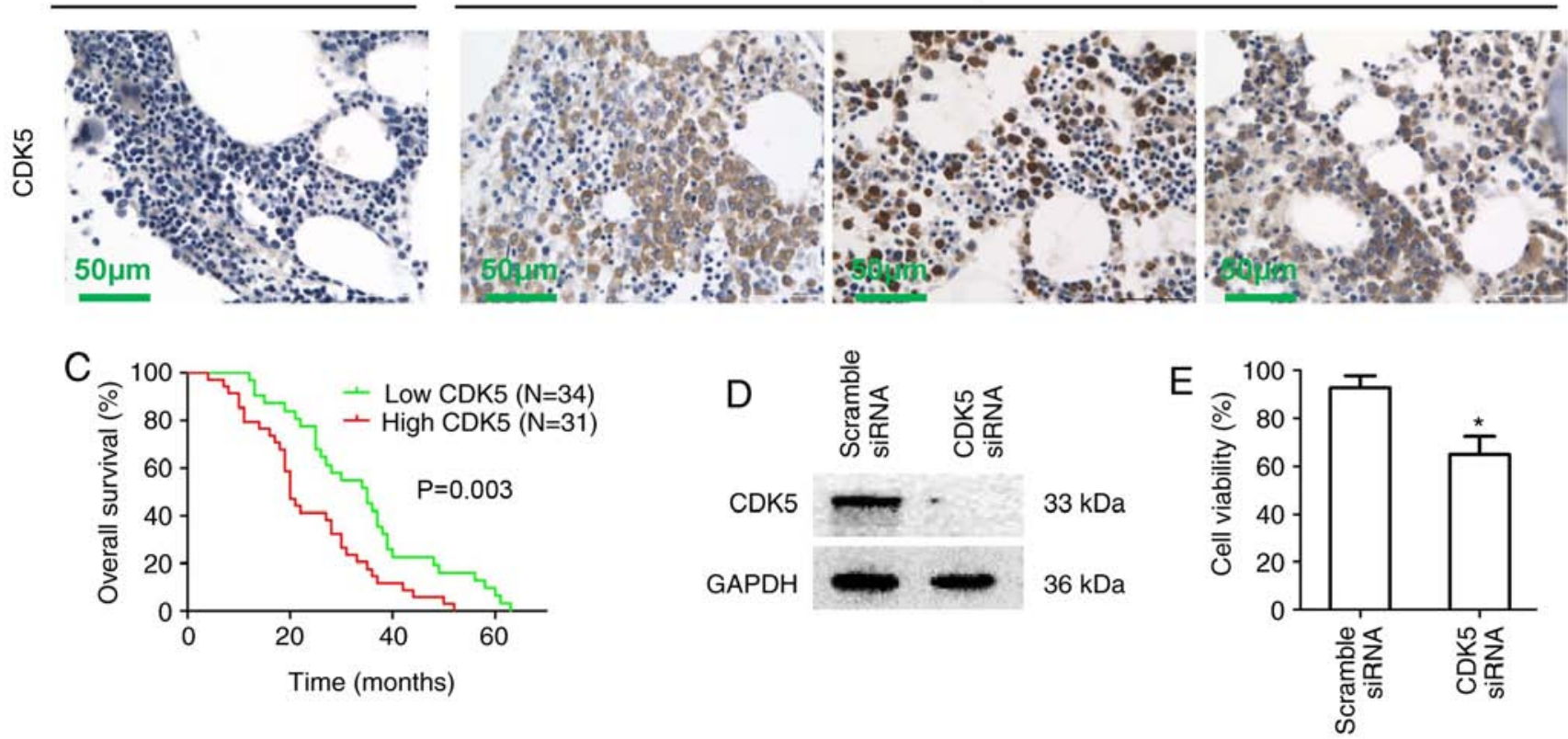

Figure 1. Characterization of CDK5 in MM. (A) BMMCs from healthy donors, MM cells from MM patients and MM cell lines were lysed in protein lysis buffer. Protein lysates were subjected to immunoblotting with a CDK5 primary antibody. GAPDH was used as a loading control. Blots shown are representative of at least three independent experiments. (B) CDK5 expression in bone marrow biopsies from normal donors and MM patients was analyzed by immunohistochemistry. Scale bar, $50 \mu \mathrm{M}$. (C) Kaplan-Meier overall survival curves for MM patients stratified by low (n=34) and high (n=31) expression of CDK5 ( $\mathrm{P}=0.003)$. (D) RPMI8226 cells were transfected with scramble siRNA, CDK5 siRNA by using the cell line Nucleofector kit V. The cells were harvested $48 \mathrm{~h}$ posttransfection and subjected to immunoblotting with CDK5 antibody. (E) RPMI8226 cells were transfected with scramble siRNA, CDK5 siRNA followed by viability analysis using MTT assay. The percentage of cell viability was normalized to scramble siRNA control. ${ }^{*} \mathrm{P}<0.05$ vs. control group. CDK, cyclin dependent kinase; si, small interfering; MM, multiple myeloma; BMMCs, bone marrow mononuclear cells.

of primary MM cells, including those who relapsed after bortezomib treatment with an IC50 of 40-80 nM (Fig. 2B), which was much lower than the that $(\sim 150 \mathrm{nM})$ in BMMCs from healthy donors (Fig. 2C).

In order to further disclose the mechanism of action underlying dinaciclib-triggered MM cell viability inhibition, cell cycle distribution assessment was conducted in RPMI8226 and H929 cells. The results showed that dinaciclib induced G2/M phase arrest in both cell lines (Fig. 2D). In accordance with these findings, dinaciclib also inhibited the expression of cyclin regulatory protein $\mathrm{CDC} 25 \mathrm{C}$ and its downstream proteins such as CDC2 and cyclin B1 in G2/M phase (Figs. 2E and $\mathrm{S} 1 \mathrm{C}$ ). The marker proteins in G1/S phase were also detected and the expression of cyclin D1, cyclin E1 or p21 did not change significantly (Fig. 2E), and the expression of p16 increased significantly (Figs. 2E and S1C).

Furthermore, dinaciclib induced apoptosis in RPMI8226 and H929 cells demonstrated by Annexin V/PI staining (Fig. 3A). Moreover, dinaciclib also increased the cleavage of PARP, a hallmark of apoptosis. The present study further examined the expression of representative endogenous (caspase 9) and exogenous (caspase 8) apoptotic proteins, and found that dinaciclib activated caspase 8 and caspase 9 followed by activation of caspase 3 (Figs. 3B and S1D).

These results suggested that restraining the expression of CDK5 by dinaciclib mediated the arrest of cell cycle and programmed cell death in MM cells. Dinaciclib induced evident inhibition of viability in both primary MM cells and MM cell lines with little killing effect on normal blood cells. This might be the theoretical basis for the slight hematological toxicity and good tolerance in human study (20).

Anti-myeloma effect of dinaciclib in vivo. Next, the anti-myeloma efficacy in vivo was detected using a MM xenograft mouse model. Fig. 4A showed MM tumors excised from mice with/without dinaciclib treatment on day 30. Treatment of RPMI8226 tumor-bearing mice with dinaciclib injection started to inhibit MM tumor growth from the day 18 compared with that of control mice (the maximum tumor diameters between the two groups were $7.8 \times 5.1 \mathrm{~mm}$ vs. $19.1 \times 13.5 \mathrm{~mm}$ on day 30 , Fig. $4 \mathrm{~A}$ and B). During the whole in vivo experiment, no significant change in body weight was noted in the dinaciclib group, suggesting that dinaciclib was well tolerated (Fig. 4C). Mechanistic study by IHC showed that the expres- 
Table I. CDK5 expression associated with the multiple clinicopathological factors in MM

\begin{tabular}{|c|c|c|c|c|}
\hline MM & $\mathrm{n}$ & $\mathrm{CDK}^{+}(\mathrm{n})$ & $\mathrm{CDK}^{-}(\mathrm{n})$ & P-value \\
\hline Bor response & & & & 0.020 \\
\hline$\geq \mathrm{PR}$ & 51 & 20 & 31 & \\
\hline $\mathrm{SD} / \mathrm{PD}$ & 14 & 11 & 3 & \\
\hline Sex & & & & 0.896 \\
\hline Male & 33 & 16 & 17 & \\
\hline Female & 32 & 15 & 17 & \\
\hline Age (years) & & & & 0.870 \\
\hline$\geq 65$ & 11 & 5 & 6 & \\
\hline$<65$ & 54 & 26 & 28 & \\
\hline D-S & & & & 0.026 \\
\hline $\mathrm{I} / \mathrm{II}$ & 19 & 5 & 14 & \\
\hline III & 46 & 26 & 20 & \\
\hline ISS & & & & 0.291 \\
\hline I & 13 & 4 & 9 & \\
\hline II/III & 52 & 27 & 25 & \\
\hline M protein & & & & 0.628 \\
\hline $\mathrm{IgG}$ & 31 & 15 & 16 & \\
\hline non-IgG & 18 & 10 & 8 & \\
\hline $\mathrm{M}$ protein & & & & 0.063 \\
\hline$\kappa$ & 32 & 19 & 13 & \\
\hline$\lambda$ & 33 & 12 & 21 & \\
\hline Plasma cells & & & & 0.188 \\
\hline$\geq 50 \%$ & 24 & 14 & 10 & \\
\hline$<50 \%$ & 41 & 17 & 24 & \\
\hline $\operatorname{HGB}(\mathrm{g} / \mathrm{l})$ & & & & 0.135 \\
\hline$\geq 100$ & 25 & 9 & 16 & \\
\hline$<100$ & 40 & 22 & 18 & \\
\hline $\mathrm{Ca}^{2+}(\mathrm{mmol} / \mathrm{l})$ & & & & 0.927 \\
\hline$\geq 2.65$ & 15 & 7 & 8 & \\
\hline$<2.65$ & 50 & 24 & 26 & \\
\hline $\mathrm{Cr}(\mu \mathrm{mol} / \mathrm{l})$ & & & & 0.614 \\
\hline$\geq 177$ & 17 & 9 & 8 & \\
\hline$<177$ & 48 & 22 & 26 & \\
\hline
\end{tabular}

MM, multiple myeloma; Ig, immunoglobulin; CDK, cyclin dependent kinase; Cr, creatinine; Bor, bortezomib; PR, partial response; $\mathrm{SD}$, stable disease; PD, progressive disease; D-S, Durie-Salmon; ISS, International Staging System; HGB, hemoglobin; Ca, calcium.

sion of CDK5 was significantly decreased and the TUNEL staining was significantly enhanced in tumors excised from mice receiving dinaciclib (Fig. 4D). Taken together, dinaciclib showed potent anti-myeloma effect in vivo by inducing apoptosis of MM cells and was well tolerated.

Combining dinaciclib with bortezomib has synergistic anti-myeloma activity. Dinaciclib exerted encouraging single-agent activity in patients with relapsed MM in an early clinical trial (20). However, at present, the treatment of MM is
Table II. Correlation of CDK5 with cytogenetic abnormalities and immunophenotypes in MM.

\begin{tabular}{|c|c|c|c|c|}
\hline MM & $\mathrm{n}$ & $\mathrm{CDK}^{+}(\mathrm{n})$ & $\mathrm{CDK}^{-}$(n) & P-value \\
\hline $17 \mathrm{p} 13$ deletion & & & & 0.914 \\
\hline Positive & 5 & 3 & 2 & \\
\hline Negative & 60 & 28 & 32 & \\
\hline $\begin{array}{l}\text { 1q21 } \\
\text { amplification }\end{array}$ & & & & 0.730 \\
\hline Positive & 35 & 16 & 19 & \\
\hline Negative & 30 & 15 & 15 & \\
\hline $\begin{array}{l}\text { IgH } \\
\text { rearrangement }\end{array}$ & & & & 0.204 \\
\hline Positive & 15 & 5 & 10 & \\
\hline Negative & 50 & 26 & 24 & \\
\hline $13 q 14$ deletion & & & & 0.179 \\
\hline Positive & 35 & 14 & 21 & \\
\hline Negative & 30 & 17 & 13 & \\
\hline CD117 & & & & 0.172 \\
\hline Positive & 16 & 10 & 6 & \\
\hline Negative & 49 & 21 & 28 & \\
\hline CD20 & & & & 0.385 \\
\hline Positive & 9 & 6 & 3 & \\
\hline Negative & 56 & 25 & 31 & \\
\hline CD56 & & & & 0.428 \\
\hline Positive & 43 & 19 & 24 & \\
\hline Negative & 22 & 12 & 10 & \\
\hline CD81 & & & & 0.789 \\
\hline Positive & 43 & 20 & 23 & \\
\hline Negative & 22 & 11 & 11 & \\
\hline CD45 & & & & 0.818 \\
\hline Positive & 24 & 11 & 13 & \\
\hline Negative & 41 & 20 & 21 & \\
\hline CD27 & & & & 0.180 \\
\hline Positive & 18 & 11 & 7 & \\
\hline Negative & 47 & 20 & 27 & \\
\hline CD28 & & & & 0.881 \\
\hline Positive & 9 & 5 & 4 & \\
\hline Negative & 56 & 26 & 30 & \\
\hline CD33 & & & & 0.456 \\
\hline Positive & 13 & 5 & 8 & \\
\hline Negative & 52 & 26 & 26 & \\
\hline
\end{tabular}

MM, multiple myeloma; CDK, cyclin dependent kinase; $\mathrm{CD}$, cluster of differentiation; Ig, immunoglobulin.

still based on multi-drug 'cocktail therapy'. If dinaciclib could play a synergistic role with existing drugs or overcome drug resistance, it would have a broader application prospect. First, it was observed that patients with high expression of CDK5 in bone marrow biopsies were less responsive to induction therapy of bortezomib (Table I, Fig. 5A). The results further 

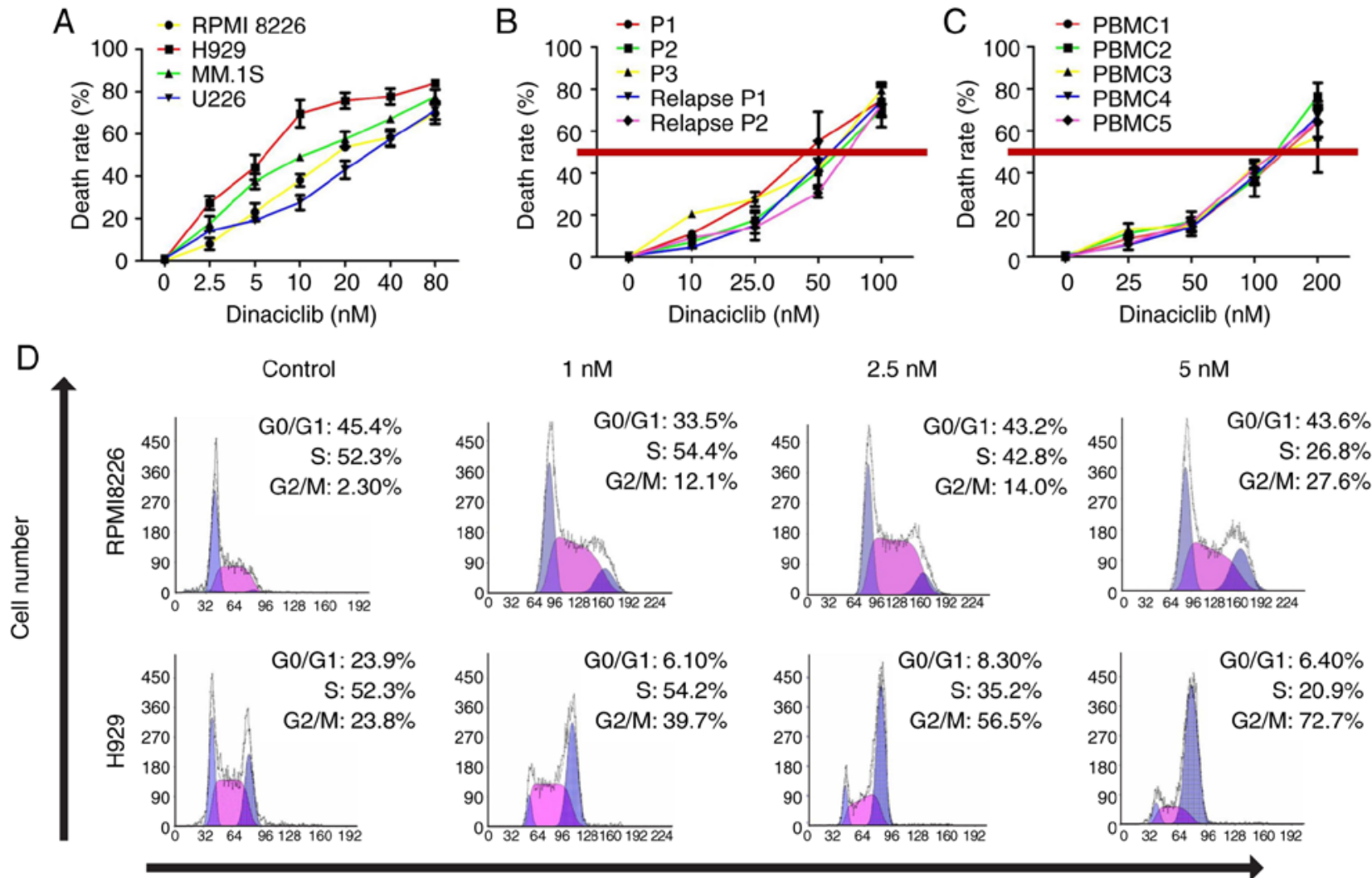

DNA content

E
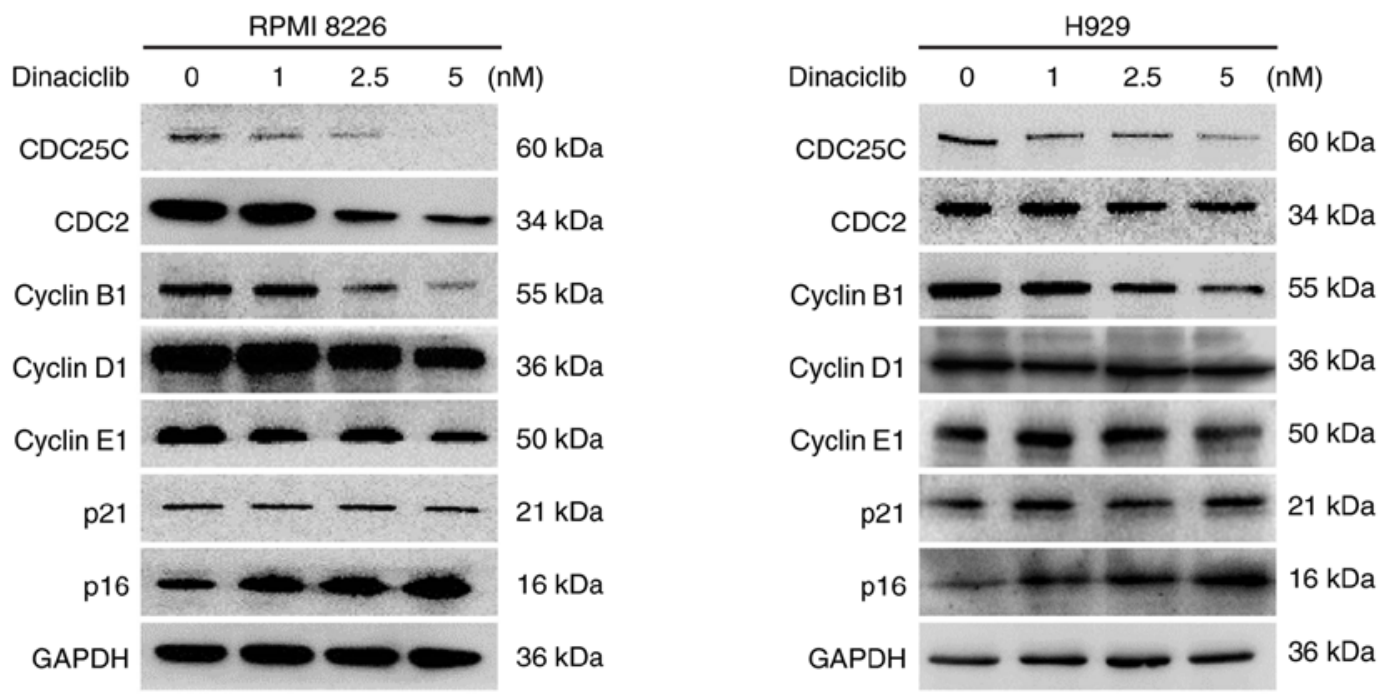

Figure 2. Effect of dinaciclib on the viability and cell cycle distribution of MM cells in vitro. (A) Multiple MM cell lines, (B) MM cells from MM patients including relapsed patients and (C) BMMCs from healthy donors were treated with dinaciclib at different concentrations for $24 \mathrm{~h}$, followed by measurement of cell viability with MTT assay. (D) RPMI8226 and H929 cells were treated with dinaciclib for $24 \mathrm{~h}$ and DNA content of cells was analyzed by flow cytometry. (E) RPMI8226 and H929 cells were treated with dinaciclib for $24 \mathrm{~h}$; protein lysates were subjected to immunoblotting with the indicated antibodies. MM, multiple myeloma; BMMCs, bone marrow mononuclear cells.

supported the view that pharmacological inhibition of CDK5 might overcome bortezomib resistance. Next synergistic experiments in RPMI8226, H929 cells and primary MM cells exposed to dinaciclib with bortezomib across a range of concentrations for $24 \mathrm{~h}$ revealed that dinaciclib and bortezomib triggered obvious synergistic anti-myeloma effect with a CI $<1.0$ (Figs. 5B and S3). A total of $5 \mathrm{nM}$ dinaciclib and 2 $\mathrm{nM}$ bortezomib, which had the most obvious synergistic effect, were selected to explore the follow-up mechanism.
Combining dinaciclib with bortezomib cooperatively suppresses the nuclear factor $(N F)-\kappa B$ signaling pathway in $M M$ cells. It is well established that the activation of $\mathrm{NF}-\kappa \mathrm{B}$ pathway is found in numerous tumors, including MM (22). One of the main anti-myeloma mechanisms of bortezomib is to inhibit the activation of the NF- $\kappa \mathrm{B}$ pathway by disturbing the ubiquitin-proteasome degradation of the inhibitor $\mathrm{I} \kappa \mathrm{B} \alpha$ of the NF- $\kappa$ B pathway (23). Therefore, the present study speculated whether the synergistic anti-myeloma effect of dinaciclib 
A
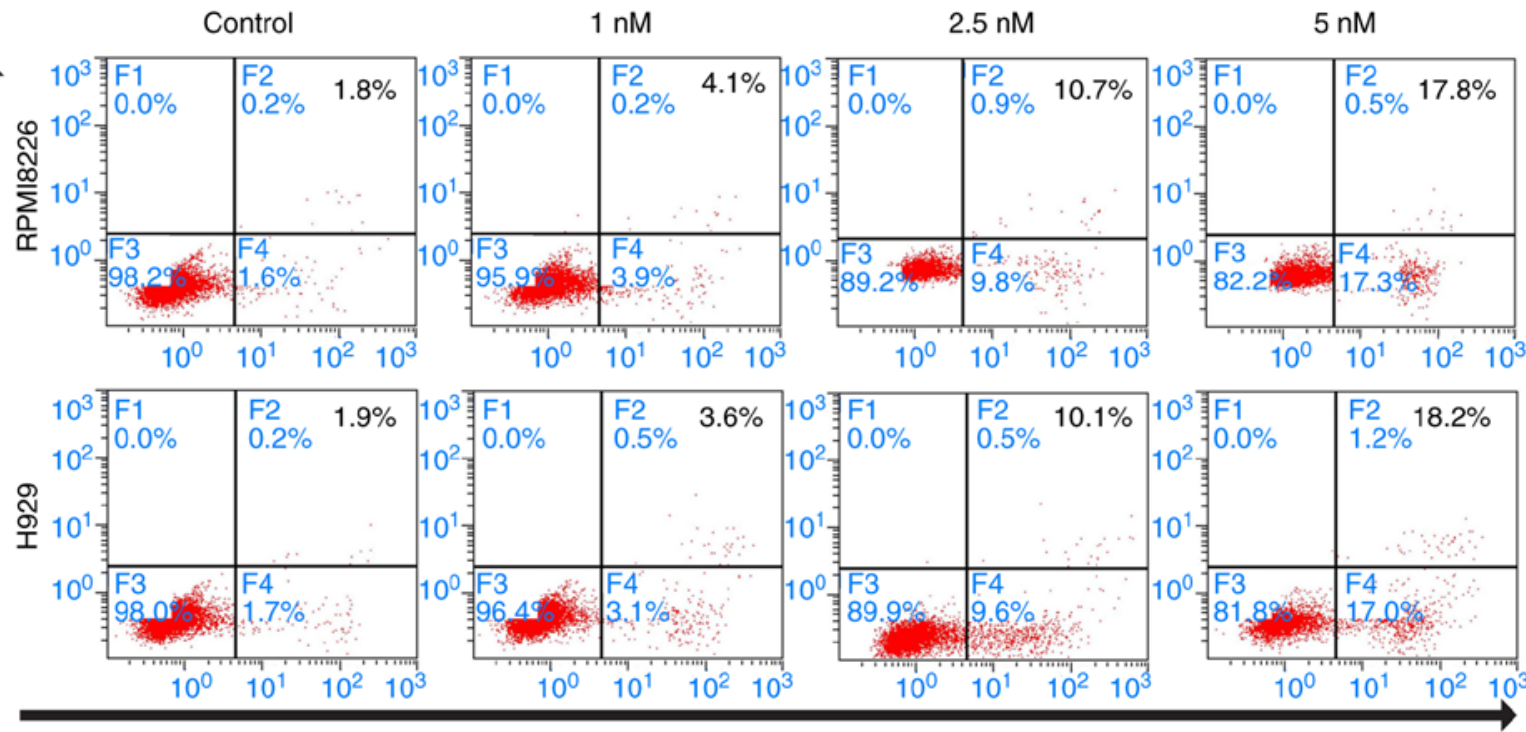

Annexin V

B

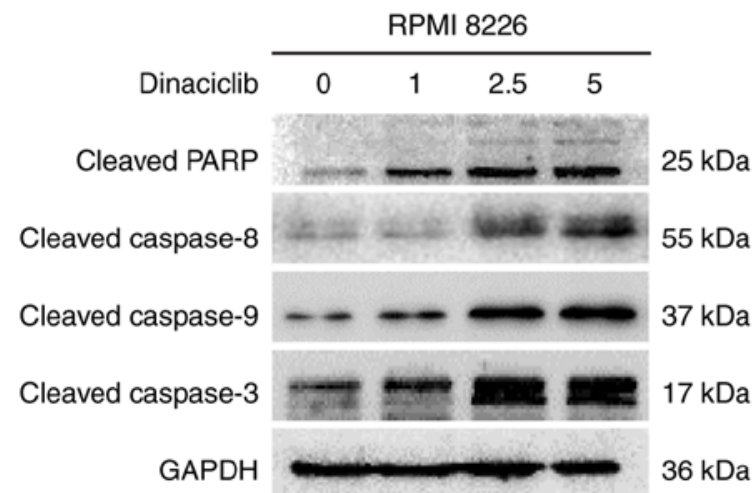

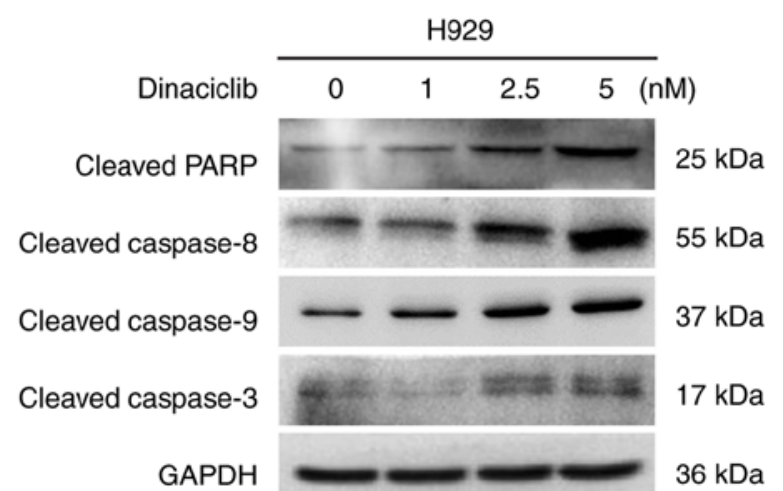

Figure 3. MM cell apoptosis induced by dinaciclib. (A) RPMI8226 and H929 cells were treated with dinaciclib for 24 h, followed by analysis for apoptosis with Annexin V/PI double staining. (B) RPMI8226 and H929 cells were treated with dinaciclib for 24 h; protein lysates were subjected to immunoblotting with the indicated antibodies. MM, multiple myeloma; PARP, poly (ADP ribose); PI, propidium iodide.

and bortezomib involved the inhibition of the NF- $\mathrm{B}$ pathway at the same time. The activation of $N F-\kappa B$ pathway is characterized by the nuclear import of the $\mathrm{NF}-\kappa \mathrm{B}$ protein (24). The present study measured the subcellular distribution of $N F-\kappa B$ p65. The results showed that the intranuclear transfer of $\mathrm{NF}-\kappa \mathrm{B}$ p65 in RPMI8226 and H929 cells treated with dinaciclib or bortezomib was lower than that in the control group; and the intranuclear transfer of p65 in the combined group was much lower than that in the single drug group (Figs. 6A and S4A), suggesting the combination of the two drugs could further inhibit the activation of the NF- $\kappa \mathrm{B}$ pathway. At the same time, the present study detected the expression levels of $\mathrm{p}-\mathrm{IKK} \alpha$ and $\mathrm{p}-\mathrm{I} \kappa \mathrm{B} \alpha$. Inhibited phosphorylation levels of IKK $\alpha$ and $\mathrm{I} \kappa \mathrm{B} \alpha$ were found in $\mathrm{MM}$ cells treated by dinaciclib alone or in combination with bortezomib (Figs. 6B and S4B), further indicating that the synergistic anti-myeloma effect of dinaciclib and bortezomib involved the simultaneous inhibition of classical NF- $\mathrm{B}$ pathway. The downstream anti-apoptotic proteins Bcl-2 and Bcl-xL were decreased and the cleaved caspase 3 was increased in MM cells treated with the combination of dinaciclib and bortezomib (Figs. 6B and S4B). These results suggested that the synergistic anti-myeloma mechanism of dinaciclib and bortezomib is involved the synchronous inhi- bition of the classical NF- $\kappa$ B pathway, which resulted in the decrease of downstream anti-apoptotic protein expression and the increase of apoptosis in MM cells.

\section{Discussion}

As an unorthodox member of CDK family, CDK5 has attracted much attention for its unconventional functions. CDK5 involves in a variety of signaling pathways and plays an important role in tumorigenesis (4). At present the role of CDK5 in the MM development, prognosis and drug resistance is still not clear. The purpose of this study is to explore the role of CDK5 in MM.

Consistent with previous study (16), the present study also found that the expression of CDK5 increased in both primary MM cells, MM cell lines and MM bone marrow biopsies. For the first time, to the best of our knowledge the current study confirmed that the overexpression of CDK5 suggested the adverse prognosis of MM. Knockout of CDK5 by siRNA suppressed the viability of MM cells, all of which suggested that CDK5 plays a key role of the pathogenesis in MM and favors a solid clinical application significance for the current research. 
A

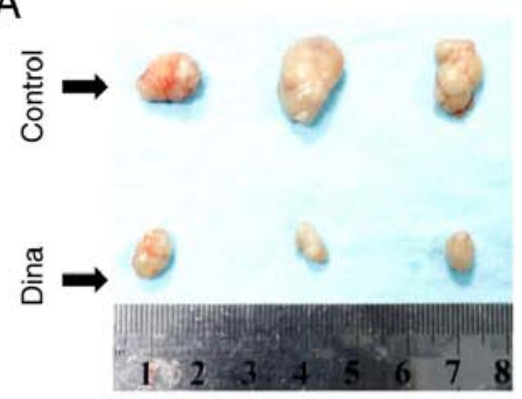

D
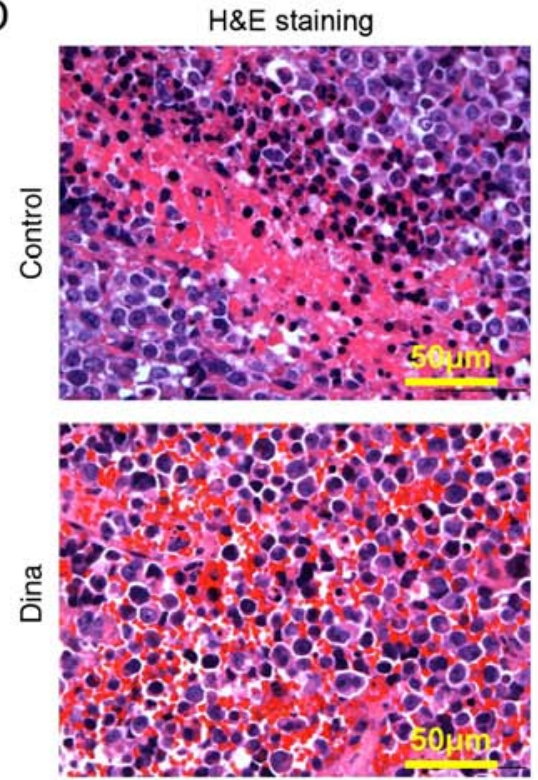

$\mathrm{B}$
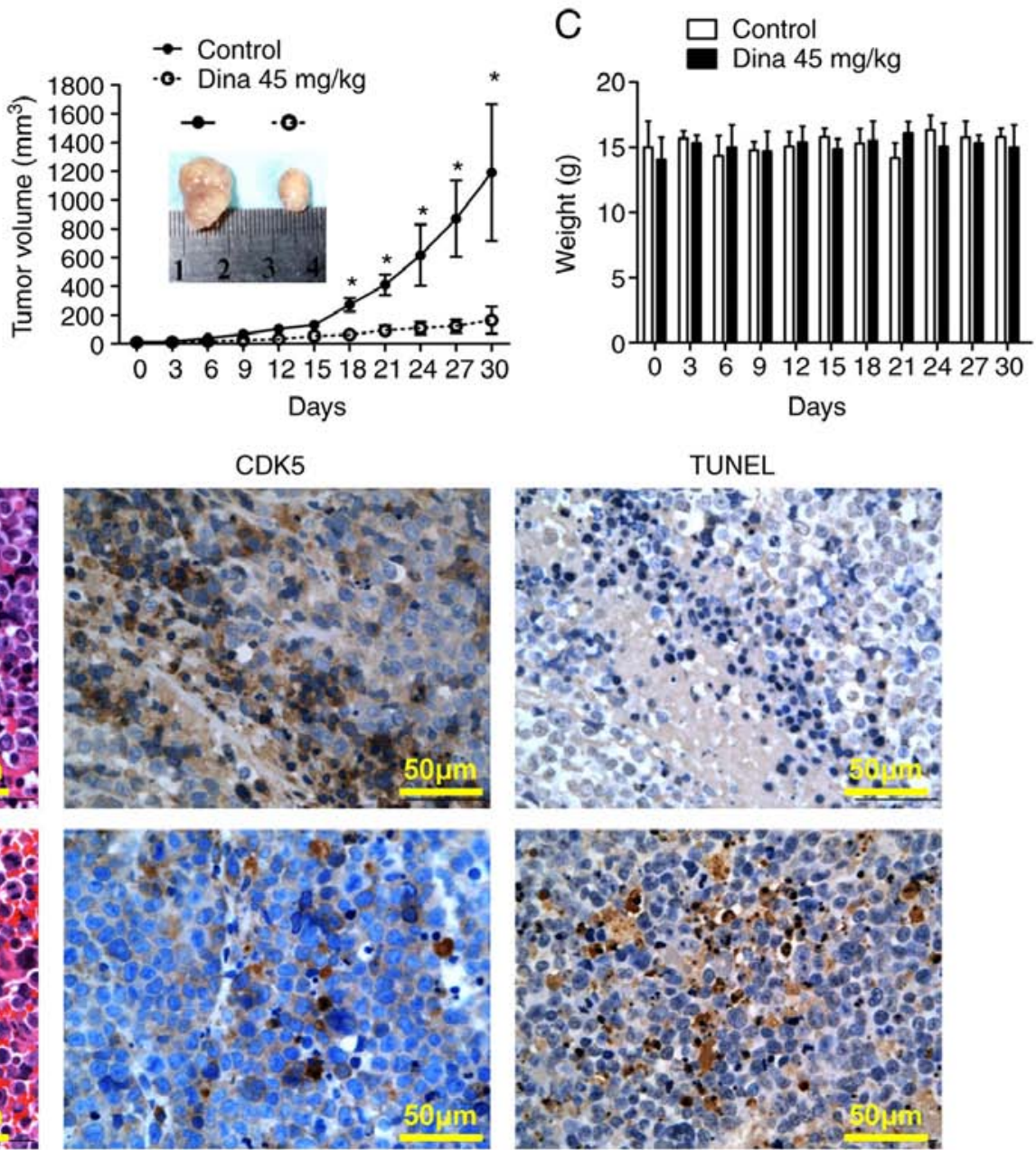

Figure 4. Anti-myeloma effect of dina in vivo. (A) Representative images of tumor excised from mice on day 30 were shown. (B) Tumor volume was measured every three day. Data shown are mean \pm SD. ${ }^{*} \mathrm{P}<0.05$ vs. control. (C) Mouse body weight was measured every three day. Data shown are mean \pm SD. (D) Tumor sections from control and dina-treated mice were immunostained with anti-CDK 5 antibody (dark brown). Scale bar, $50 \mu \mathrm{M}$. Apoptotic cells were identified by a TUNEL assay (TUNEL-positive cells: Dark brown), as well as H\&E staining. Photographs are representative of similar observations in three different mice receiving same treatment. SD, standard deviation; CDK, cyclin dependent kinase; H\&E, hematoxylin and eosin; TUNEL, terminal deoxynucleotidyl-transferase-mediated dUTP nick end labelling; dina, dinaciclib.

Dinaciclib, a small molecule inhibitor of CDK1/2/5/9, has been shown to interfere with DNA damage repair in MM cells (18) and suppress the proliferation of MM cells by inducing endoplasmic reticulum stress in a CDK1/5 dependent manner (19). However, the mechanism of its inhibition on MM cell viability remains to be further studied. RPMI8226 and H929 cells were treated with different concentrations of dinaciclib and detected the expression of target molecules. It was unexpectedly found that the inhibitory effect of $5 \mathrm{nM}$ dinaciclib on CDK5 was better than that on other molecules. Therefore, dinaciclib could be used as a specific inhibitor of CDK5 to carry out follow-up studies on the function of CDK5 in MM.

First, the effect of pharmacological inhibition of CDK5 by dinaciclib on MM cells was studied. It was shown that dinaciclib caused an obvious decrease in cell viability in various MM cell lines and MM cells from patients including those relapsed after bortezomib treatment, suggesting that it might overcome proteasome inhibitors resistance. At the same time, the present study found that dinaciclib did not affect the normal viability of BMMCs, exhibiting its high selectivity to cancer cells and safety to normal cells, which was also consistent with good tolerance as suggested by an early clinical study of dinaciclib (20).

Unlike other CDKs, CDK5 was not considered to have the function of regulating the cell cycle previously. However, it has been found that retinoblastoma protein $(\mathrm{Rb})$, as a downstream target molecule of CDK5, can be directly phosphorylated by CDK5, thus affecting the process of the cell cycle (25). The current results showed that pharmacological inhibition of CDK5 resulted in the stagnation of MM cells in the G2/M phase, while the expression of CDC25c, CDC2 and cyclinB1 in $\mathrm{G} 2 / \mathrm{M}$ phase decreased; and cyclinD1 and cyclinE1 in G1/S phase remained unchanged. Unlike the results of Abbas and Dutta (26), the expression of p21 did not change significantly, but the expression of p16 increased. Previous studies have shown that CDK5 and p16 are both upstream regulators of $\mathrm{Rb}$. Inhibition of CDK5 or upregulation of p16 both result in a decrease in phosphorylated $\mathrm{Rb}$ expression $(25,27)$. Therefore, the present study supposed that after pharmacological inhibition of CDK5, the expression of phosphorylated $\mathrm{Rb}$ decreased, resulting in a feedback enhancement 
A

$\geq \mathrm{PR}$
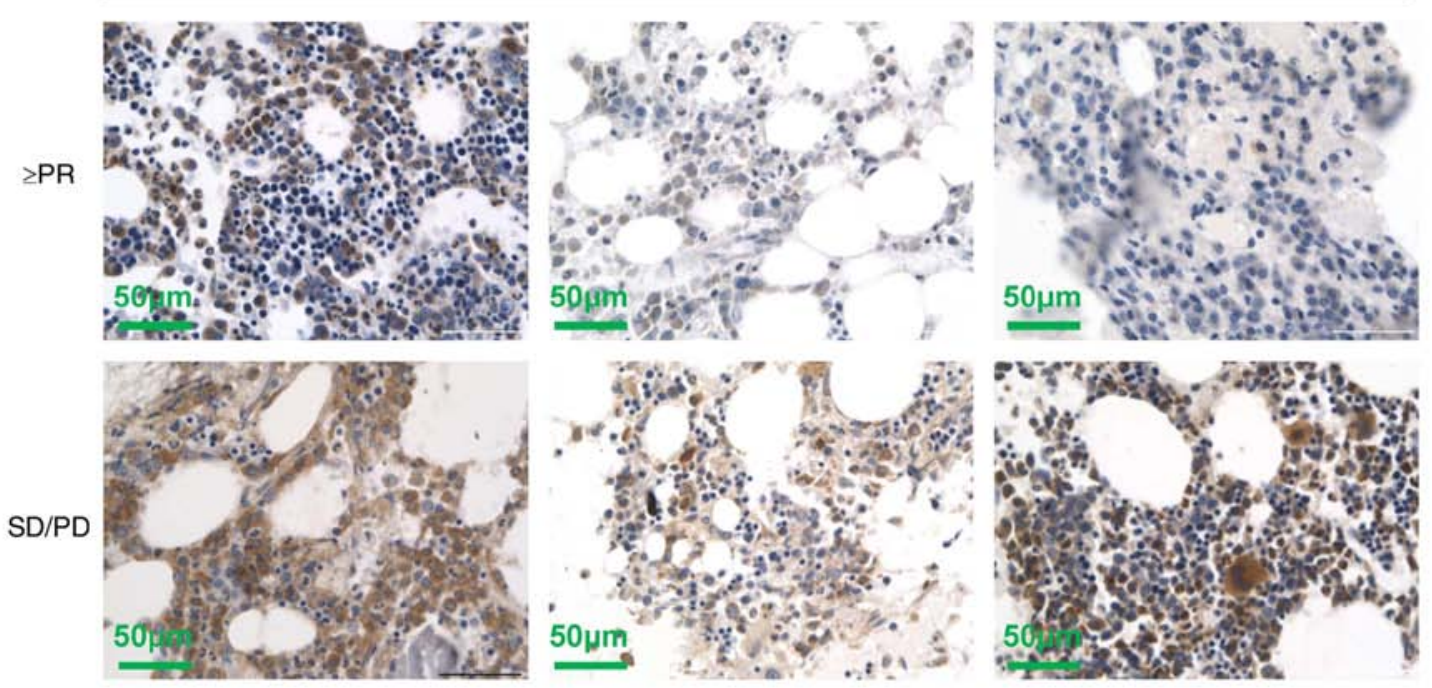

B

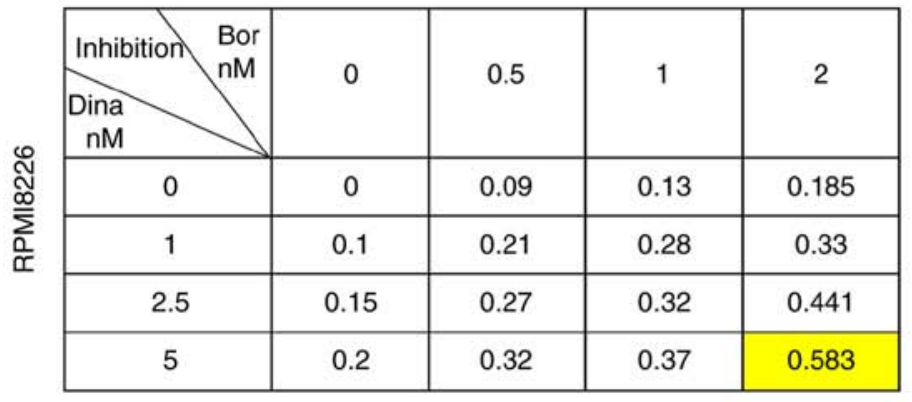

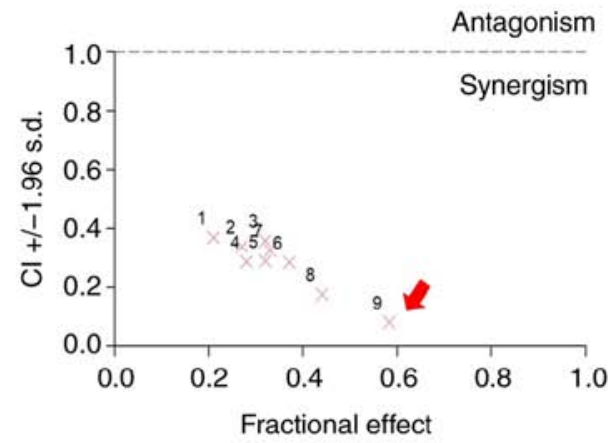

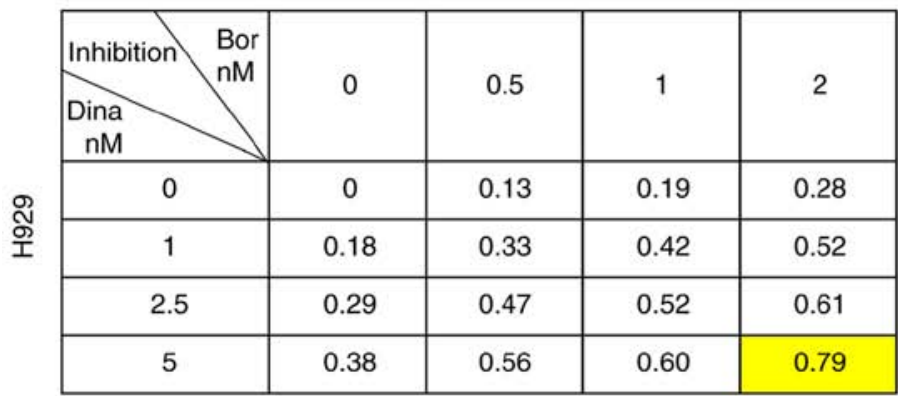

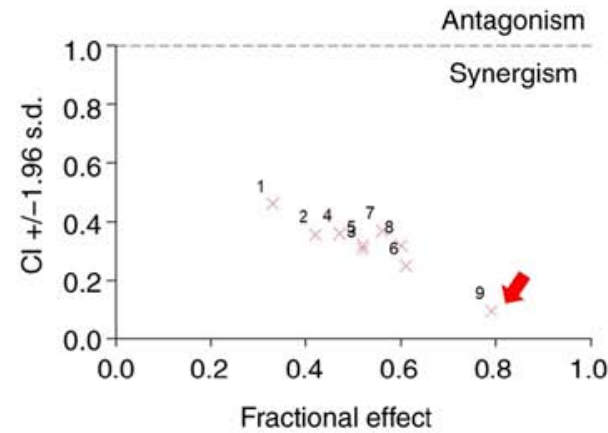

Figure 5. Combination of dina and bor shows synergistic effect in MM. (A) CDK5 expression in bone marrow biopsies from MM patients was analyzed by immunohistochemistry. Scale bar, $50 \mu \mathrm{M}$. (B) RPMI8226 and H929 cells were treated for $24 \mathrm{~h}$ with dina, bor, or dina plus bor and then assessed for viability by using the MTT assay. Isobologram analysis shows the synergistic cytotoxic effect of dina and bor. The graphs (right panel) are derived from the values given in the tables (left panel). $\mathrm{CI}<1$ indicates synergy. MM, multiple myeloma; CDK, cyclin dependent kinase; CI, confidence interval; dina, dinaciclib; bor, bortezomib.

of p16 expression (28). Of course, the complete mechanisms still need to be further studied.

The results from flow cytometry and western blotting suggested that pharmacological inhibition of CDK5 significantly induced apoptosis of MM cells via activation of caspases. The expression of endogenous (caspase 9) and exogenous (caspase 8) apoptotic proteins was detected and it was found that dinaciclib activated both endogenous and exogenous apoptotic pathways followed by activation of caspase 3 .

Having conducted in vitro studies, the in vivo effects of dinaciclib were also verified. A MM-bearing mice model was established, which was administered by intermittent injection of dinaciclib. A marked reduction in tumor volume was noted in mice experiencing dinaciclib vs. mice receiving vehicle alone. With the prolongation of administration time, there was no significant change in body weight, indicating that dinaciclib was well tolerated in vivo. The outstanding anti-myeloma activity of dinaciclib in vivo was also confirmed by IHC analysis for apoptosis (TUNEL stain) and CDK5 expression of tumor sections from control or dinaciclib-treated mice.

In conclusion, it was confirmed that dinaciclib had an excellent anti-myeloma effect, including in vivo/vitro experiments and primary MM cells, which provided a further theoretical basis for dinaciclib as a new drug for the treatment of MM. 
A

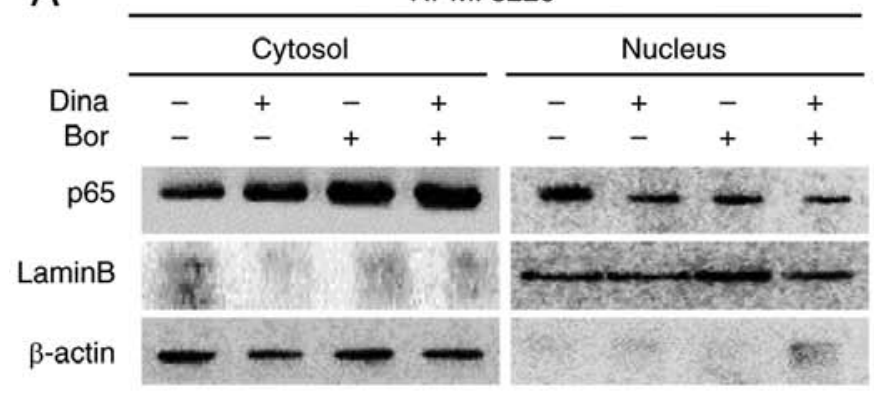

B

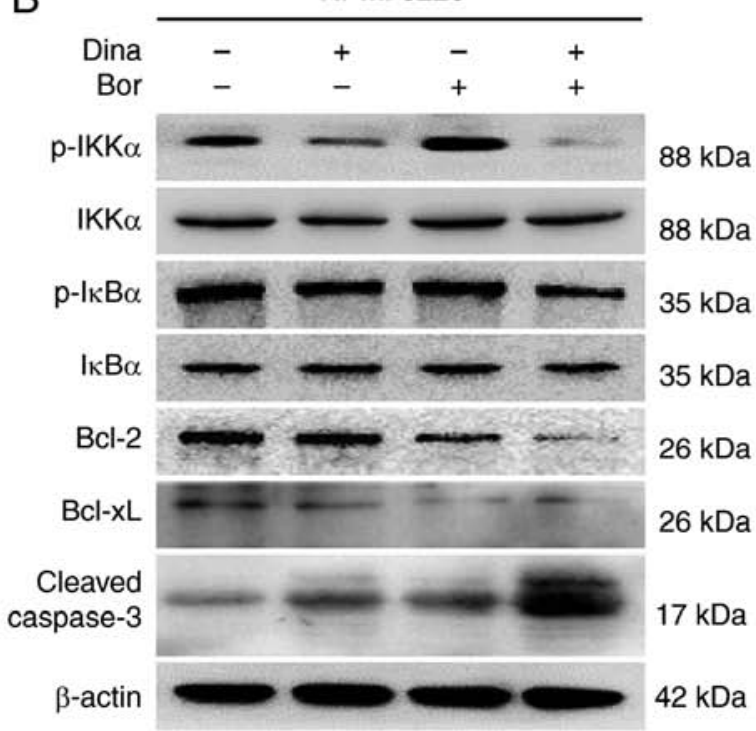

H929

\begin{tabular}{|c|c|c|c|c|c|c|c|}
\hline \multicolumn{3}{|c|}{ Cytosol } & \multicolumn{4}{|c|}{ Nucleus } & \\
\hline- & + & + & - & + & - & + & \\
\hline- & - & + & - & - & + & + & \\
\hline 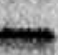 & & & - & $t$ & $\operatorname{se}$ & & $65 \mathrm{kD}$ \\
\hline 4 & & & & & & $\longrightarrow$ & $68 \mathrm{~kL}$ \\
\hline 0 & - & & & - neves & was & Wais? & $\mathrm{kL}$ \\
\hline
\end{tabular}

Figure 6. Basal protein levels of the NF-kB signaling pathway and apoptotic pathway in the synergistic model. (A) RPMI8226 and H929 cells were treated for $24 \mathrm{~h}$ with dina, bor, or dina plus bor; NF- $\mathrm{\kappa B}$ subunit $\mathrm{p} 65$ in cytosol and nucleus was detected respectively. GAPDH and LaminB was used as a loading control. (B) RPMI8226 and H929 cells were treated for $24 \mathrm{~h}$ with dina, bor, or dina plus bor; protein lysates were subjected to immunoblotting with the indicated antibodies. NF, nuclear factor; p-, phosphorylated; dina, dinaciclib; bor, bortezomib.

In terms of the current treatment strategy of MM, combination therapy is a better choice. The resistance of first-line bortezomib has always been an urgent clinical problem. So, the combined effects of dinaciclib and bortezomib on MM cells were subsequently tested in order to find new strategies to enhance the sensitivity of bortezomib.

It has been reported that CDK5 may touch upon the resistance of MM to proteasome inhibitors, but only the preliminary mechanism has been discussed, which is thought be related to miR-27a-5p or PSMB5 $(15,17,29)$. The correlation between the expression of CDK 5 in bone marrow biopsies and the response of MM patients to proteasome inhibitors bortezomib was analyzed. The results indicated that MM patients with high expression of CDK5 at diagnosis had a poor response to bortezomib, suggesting that CDK5 might play an important role in bortezomib resistance. It was also demonstrated that MM patients with high CDK5 expression tended to have higher DS stage, indicating that target organ damage was more serious in patients with high CDK5 expression. Further in vitro experiments were carried out and it was found that CDK5 inhibitors and bortezomib showed synergistic anti-myeloma effect, further suggesting that targeting CDK5 is probably one of the ways to solve the problem of bortezomib resistance.
The mutation of NF- $\mathrm{kB}$ pathway and the interaction with the MM microenvironment lead to the over-activation of the NF- $\mathrm{KB}$ pathway in MM, which promotes the transcriptional activation of downstream oncogenes, the enhanced expression of gene encoding anti-apoptotic proteins, and the suppressed expression of gene encoding proapoptotic proteins (22). The present study wondered whether CDK5 was also involved in the activation of the NF- $\mathrm{KB}$ pathway. The current results confirmed that dinaciclib combined with bortezomib further inhibited the activation of the NF- $\mathrm{KB}$ pathway, resulting in the decrease of downstream anti-apoptotic protein expression, thereby inducing apoptosis and exerting a synergistic anti-myeloma effect. The regulation of the classical pathway of NF- $\mathrm{kB}$ involves numerous kinds of phosphorylation events. IKK $\alpha$ phosphorylation participates in the activation of the trimeric I $\kappa$ B kinase (IKK) complex (IKK $\alpha /$ IKK $\beta / N E M O)$ and the activation of IKK tripolymer phosphorylates IкB, which leads to the degradation of ubiquitin-proteasome pathway of IкB and the activation of the classical pathway of NF- $\mathrm{kB}$ (30). After dinaciclib exposure, the expression of $\mathrm{p}-\mathrm{IKK} \alpha$ and $\mathrm{p}-\mathrm{IKB} \alpha$ in MM cells decreased, indicating that the phosphorylation levels of some key proteins in the classical pathway of NF- $\mathrm{KB}$ changed after targeted inhibition of CDK5. 
Whether CDK5 could directly phosphorylate $\operatorname{IKK} \alpha, \operatorname{IKB} \alpha$ or other molecules needs further study.

Collectively, the present study established the potent role of CDK5 in the pathogenesis and prognosis of MM, and confirmed the promising anti-myeloma effect of CDK5 inhibitors through functional experiments in vitro and in vivo. Dinaciclib combined with bortezomib exert synergistic anti-myeloma effect by collectively inhibiting the activation of the NF- $\mathrm{NB}$ pathway in MM. This study provided the proof of concept for targeting CDK5 as a new method to improve outcome of MM patients and overcome the obstacle of bortezomib resistance.

\section{Acknowledgements}

Not applicable.

\section{Funding}

The present study was supported by grants from the Social Development Science and Technology Fund of Shaanxi Province 2016SF071 (to HT).

\section{Availability of data and materials}

The datasets used and/or analyzed during the current study are available from the corresponding author on reasonable request.

\section{Authors' contributions}

HT, LX, XC, LY, JF, GL, HZ, SG, YY, YZ, ZT, LH and SY performed experiments; HT, XC and GG wrote the paper. HT and GG conceived the strategy, oversaw the experiments and provided overall guidance and interpretation of the results. All authors read and approved the final manuscript.

\section{Ethics approval and consent to participate}

All studies have been approved by the Ethics Committee of Xijing Hospital and the Animal Ethics Committee of Fourth Military Medical University, Xi'an, Shaanxi, China. Informed consent was obtained from all patients, in accordance with the Helsinki Protocol. These studies have been approved by the Ethics Committee of Xijing Hospital.

\section{Patient consent for publication}

Not applicable.

\section{Competing interests}

The authors declare no potential conflicts of interest.

\section{References}

1. Asghar U, Witkiewicz AK, Turner NC and Knudsen ES: The history and future of targeting cyclin-dependent kinases in cancer therapy. Nat Rev Drug Discov 14: 130-146, 2015.

2. Casimiro MC, Crosariol M, Loro E, Li Z and Pestell RG: Cyclins and cell cycle control in cancer and disease. Genes Cancer 3 . 649-657, 2012
3. Dhavan R and Tsai LH: A decade of CDK5. Nat Rev Mol Cell Biol 2: 749-759, 2001.

4. Shupp A, Casimiro MC and Pestell RG: Biological functions of CDK5 and potential CDK5 targeted clinical treatments. Oncotarget 8: 17373-17382, 2017.

5. Zhang X, Zhong T, Dang Y, Li Z, Li P and Chen G: Aberran expression of CDK5 infers poor outcomes for nasopharyngeal carcinoma patients. Int J Clin Exp Pathol 8: 8066-8074, 2015.

6. Zhuang K, Zhang J, Xiong M, Wang X, Luo X, Han L, Meng Y, Zhang Y, Liao W and Liu S: CDK5 functions as a tumor promoter in human colorectal cancer via modulating the ERK5-AP-1 axis. Cell Death Dis 7: e2415, 2016.

7. Zhang R, Lin P, Yang H, He Y, Dang YW, Feng ZB and Chen G: Clinical role and biological function of CDK5 in hepatocellular carcinoma: A study based on immunohistochemistry, RNA-seq and in vitro investigation. Oncotarget 8: 108333-108354, 2017.

8. Pan DH, Zhu ML, Lin XM, Lin XG, He RQ, Ling YX, Su ST, Wickramaarachchi MM, Dang YW, Wei KL and Chen G: Evaluation and clinical significance of cyclin-dependent kinase5 expression in cervical lesions: A clinical research study in Guangxi, China. Eur J Med Res 21: 28, 2016.

9. Wei K, Ye Z, Li Z, Dang Y, Chen X, Huang N, Bao C, Gan T, Yang L and Chen G: An immunohistochemical study of cyclin-dependent kinase 5 (CDK5) expression in non-small cell lung cancer (NSCLC) and small cell lung cancer (SCLC): A possible prognostic biomarker. World J Surg Oncol 14: 34, 2016.

10. Sun SS, Zhou X, Huang YY, Kong LP, Mei M, Guo WY,Zhao MH, Ren Y, Shen Q and Zhang L: Targeting STAT3/miR-21 axis inhibits epithelial-mesenchymal transition via regulating CDK5 in head and neck squamous cell carcinoma. Mol Cancer 14: 213, 2015.

11. Zhang S, Lu Z, Mao W, Ahmed AA, Yang H, Zhou J, Jennings N, Rodriguez-Aguayo C, Lopez-Berestein G, Miranda R, et al: CDK5 regulates paclitaxel sensitivity in ovarian cancer cells by modulating AKT activation, p21Cip1- and p27Kip1-Mediated G1 cell cycle arrest and apoptosis. PLoS One 10: e0131833, 2015.

12. Li R, Liu GZ, Luo SY, Chen R and Zhang JX: Cyclin I promotes cisplatin resistance via Cdk5 activation in cervical cancer. Eur Rev Med Pharmacol Sci 19: 4533-4541, 2015.

13. Ehrlich SM, Liebl J, Ardelt MA, Lehr T, De Toni EN, Mayr D, Brandl L, Kirchner T, Zahler S, Gerbes AL and Vollmar AM: Targeting cyclin dependent kinase 5 in hepatocellular carcinoma-A novel therapeutic approach. J Hepatol 6: 102-113, 2015.

14. Merk H,Zhang S,LehrT, Müller C,Ulrich M, Bibb JA, Adams RH, Bracher F, Zahler S, Vollmar AM and Liebl J: Inhibition of endothelial Cdk5 reduces tumor growth by promoting non-productive angiogenesis. Oncotarget 7: 6088-6104, 2016.

15. Ri M: Endoplasmic-reticulum stress pathway-associated mechanisms of action of proteasome inhibitors in multiple myeloma. Int J Hematol 104: 273-280, 2016.

16. Levacque Z, Rosales JL and Lee KY: Level of cdk5 expression predicts the survival of relapsed multiple myeloma patients. Cell Cycle 11: 4093-4095, 2012.

17. Zhu YX, Tiedemann R, Shi CX, Yin H, Schmidt JE, Bruins LA, Keats JJ, Braggio E, Sereduk C, Mousses S and Stewart AK: RNAi screen of the druggable genome identifies modulators of proteasome inhibitor sensitivity in myeloma including CDK5. Blood 117: 3847-3857, 2011.

18. Alagpulinsa DA, Ayyadevara S, Yaccoby S and Shmookler Reis RJ: A cyclin-dependent kinase inhibitor, dinaciclib, impairs homologous recombination and sensitizes multiple myeloma cells to PARP inhibition. Mol Cancer Ther 15: 241-250, 2016.

19. Nguyen TK and Grant S: Dinaciclib (SCH727965) inhibits the unfolded protein response through a CDK1- and 5-dependent mechanism. Mol Cancer Ther 13: 662-674, 2014.

20. Kumar SK, LaPlant B, Chng WJ, Zonder J, Callander N, Fonseca R, Fruth B, Roy V, Erlichman C, Stewart AK, et al: Dinaciclib, a novel CDK inhibitor, demonstrates encouraging single-agent activity in patients with relapsed multiple myeloma. Blood 125: 443-448, 2015.

21. Tang H, Shu M, Dai B, Xu L, Dong B, Gao G and Chen X: DNA damage response-initiated cytokine secretion in bone marrow stromal cells promotes chemoresistance of myeloma cells. Leuk Lymphoma 59: 2220-2226, 2018.

22. Roy P, Sarkar UA and Basak S: The NF- $\mathrm{BB}$ activating pathways in multiple myeloma. Biomedicines 6: pii: E59, 2018.

23. Hideshima T, Chauhan D, Richardson P, Mitsiades C, Mitsiades N, Hayashi T, Munshi N, Dang L, Castro A, Palombella V, et al: NF-kappa B as a therapeutic target in multiple myeloma. J Biol Chem 277: 16639-16647, 2002. 
24. Hoffmann A, Natoli G and Ghosh G: Transcriptional regulation via the NF-kappaB signaling module. Oncogene 25: 6706-6716, 2006.

25. Pozo K, Castro-Rivera E, Tan C, Plattner F, Schwach G, Siegl V, Meyer D, Guo A, Gundara J, Mettlach G, et al: The role of Cdk5 in neuroendocrine thyroid cancer. Cancer Cell 24: 499-511, 2013.

26. Abbas T and Dutta A: p21 in cancer: Intricate networks and multiple activities. Nat Rev Cancer 9: 400-414, 2009.

27. Burkhart DL and Sage J: Cellular mechanisms of tumour suppression by the retinoblastoma gene. Nat Rev Cancer 8: 671-682, 2008

28. Tang H, Xu L, Liang X and Gao G: Low dose dinaciclib enhances doxorubicin-induced senescence in myeloma RPMI8226 cells by transformation of the p21 and p16 pathways. Oncol Lett 16: 6608-6614, 2018.
29. Ballabio E, Armesto M, Breeze CE, Manterola L, Arestin M, Tramonti D, Hatton CS and Lawrie $\mathrm{CH}$ : Bortezomib action in multiple myeloma: MicroRNA-mediated synergy (and miR-27a/CDK5 driven sensitivity)? Blood Cancer J 2: e83, 2012.

30. Oeckinghaus A and Ghosh S: The NF-kappaB family of transcription factors and its regulation. Cold Spring Harb Perspect Biol 1: a000034, 2009.

(i) (2) This work is licensed under a Creative Commons

EY NO NO Attribution-NonCommercial-NoDerivatives 4.0 International (CC BY-NC-ND 4.0) License. 